\title{
Repair of articular cartilage defects by tissue-engineered cartilage constructed with adipose-derived stem cells and acellular cartilaginous matrix in rabbits
}

\author{
Z.J. Wang, R.Z. An, J.Y. Zhao, Q. Zhang, J. Yang, J.B. Wang, G.Y. Wen, \\ X.H. Yuan, X.W. Qi, S.J. Li and X.C. Ye \\ Department of Orthopedics Surgery, \\ The Fifth Affiliated Hospital of Zunyi Medical College, Zhuhai, China \\ Corresponding author: Z.J. Wang \\ E-mail: zhaojiewangcn@163.com
}

Genet. Mol. Res. 13 (2): 4599-4606 (2014)

Received June 12, 2013

Accepted October 25, 2013

Published June 18, 2014

DOI http://dx.doi.org/10.4238/2014.June.18.2

\begin{abstract}
After injury, inflammation, or degeneration, articular cartilage has limited self-repair ability. We aimed to explore the feasibility of repair of articular cartilage defects with tissue-engineered cartilage constructed by acellular cartilage matrices (ACMs) seeded with adipose-derived stem cells (ADSCs). The ADSCs were isolated from 3-month-old New Zealand albino rabbit by using collagenase and cultured and amplified in vitro. Fresh cartilage isolated from adult New Zealand albino rabbit were freeze-dried for $12 \mathrm{~h}$ and treated with Triton X-100, DNase, and RNase to obtain ACMs. ADSCs were seeded in the acellular cartilaginous matrix at $2 \times 10^{7} / \mathrm{mL}$, and cultured in chondrogenic differentiation medium for 2 weeks to construct tissueengineered cartilage. Twenty-four New Zealand white rabbits were randomly divided into A, B, and C groups. Engineered cartilage was transplanted into cartilage defect position of rabbits in group A, group $\mathrm{B}$ obtained ACMs, and group $\mathrm{C}$ did not receive any transplants. The
\end{abstract}


rabbits were sacrificed in week 12 . The restored tissue was evaluated using macroscopy, histology, immunohistochemistry, and transmission electron microscopy (TEM). In the tissue-engineered cartilage group (group A), articular cartilage defects of the rabbits were filled with chondrocyte-like tissue with smooth surface. Immunohistochemistry showed type II-collagen expression and Alcian blue staining was positive. TEM showed chondrocytes in the recesses, with plenty of secretary matrix particles. In the scaffold group (group B), the defect was filled with fibrous tissue. No repaired tissue was found in the blank group (group C). Tissue-engineered cartilage using ACM seeded with ADSCs can help repair articular cartilage defects in rabbits.

Key words: Adipose-derived stem cell; Acellular cartilaginous matrix; Cartilage; Tissue engineering

\section{INTRODUCTION}

Injured articular cartilage has limited self-repair capacity because of lack of dominating blood supply. Cartilage damage caused by trauma, infection, and degenerative diseases can cause long-term joint pain and dysfunction, as well as joint disuse, which causes great pain and discomfort. The traditional cartilage repair methods mainly include subchondral drilling (Mithoefer et al., 2005), microfracture surgery (Takao et al., 2004), and periosteum transplantation (Vijayan et al., 2012). Its purpose is to mobilize a variety of cells to proliferate and differentiate into chondrocyte to achieve the purpose of repair and reconstruction. However, the repaired tissue is often fibrocartilage (Grande et al., 1999) instead of hyaline cartilage, and further degradation and ossification is possible; therefore, the overall therapeutic effect is poor.

In recent years, cartilage tissue-engineering technology has developed very quickly, which has provided new ways to solve this difficult problem (Redman et al., 2005; Karlsson et al., 2007; Yoon et al., 2011; Coburn et al., 2013; van Lent and van den Berg, 2013). One of the current focuses in cartilage tissue engineering is to identify a suitable chondrocyte scaffold (Meretoja et al., 2013). Acellular cartilaginous matrix (ACM) is a recently developed natural matrix material. Because it removes the antigen part, it has good biocompatibility and is widely used in tissue engineering (Badylak and Obermiller, 2003).

In 2002, Zuk et al. found some cells in human and mouse adipose tissues with selfrenewal capacity, long-term viability, and multilineage potential. These cells are called adipose-derived stem cells (ADSCs). In 2003, Gimble and Guilak used various ways to induce adipose-derived adult stem cells to differentiate along the adipocyte, chondrocyte, myocyte, neuronal, and osteoblast lineages, which further confirmed the stem cell property of these ADSCs.

Construction of cartilage tissue is affected by many factors, including seed cells, cytokines, carrier and other factors in vitro. How to assign the 3 factors in the most appropriate proportion to construct an ideal tissue-engineered cartilage is an important issue at present. In this study, we evaluated the healing behavior of rabbit articular defects repaired by tissueengineered cartilage constructed by articular ACMs seeded with ADSCs to provide a new method for the treatment of articular cartilage defects. 


\title{
MATERIAL AND METHODS
}

\begin{abstract}
Animals
Randomly selected male and female New Zealand white rabbits, weighing about 2.5-4.0 kg, SPF grade, were provided by Guangdong Medical Experimental Animal Center (Guangzhou, China). This study was carried out in strict accordance with the recommendations in the Guide for the Care and Use of Laboratory Animals of the National Institutes of Health. The animal use protocol has been reviewed and approved by the Institutional Animal Care and Use Committee (IACUC) of Zunyi Medical College.
\end{abstract}

\section{Subculture of ADSCs}

Adipose tissue samples, about $3 \mathrm{~g}$, were collected from the back of New Zealand white rabbit (3 months old). Blood vessels and other parts such as superficial fascia were removed. Tissue was rinsed with phosphate-buffered saline several times, and torn by scissors. Tissue was digested $20-30 \mathrm{~min}$ on $0.1 \%$ type I collagenase (Sigma, USA) at $37^{\circ} \mathrm{C}$ in a gently stirred water bath. The same volume of complete culture medium was used to neutralize. Followed by centrifugation at $1000 \mathrm{~g}$ for $10 \mathrm{~min}$, the supernatant was discarded and the precipitate was resuspended and filtered with 80-mesh Nylon filter. The cell viability was analyzed with Trypan blue. Cells were cultured in DMEM (Dulbecco's modified Eagle's medium) supplemented with $10 \%$ FBS (fetal bovine serum), and incubated overnight at $37^{\circ} \mathrm{C}, 5 \% \mathrm{CO}_{2}$ incubator. Cells were split when they reached $80 \%$ confluence. Cells of passage No. 3 were used in the experiment.

\section{Preparation of ACM}

Adult rabbit ear cartilage was collected surgically and prepared to the size of $5 \mathrm{~mm} x$ $5 \mathrm{~mm} \times 1 \mathrm{~mm}$. Tissue was frozen dried in liquid nitrogen for $12 \mathrm{~h}$. The tissue was processed as follows: 1) The cartilage tissue was shaken consistently in PMSF $(0.35 \mathrm{~mL} / \mathrm{L})$, low osmotic Tris- $\mathrm{HCl}$ buffer, $\mathrm{pH}=7.4,4^{\circ} \mathrm{C}$ for $24 \mathrm{~h}$. 2) $10 \mathrm{~g} / \mathrm{L}$ Triton $\mathrm{X}-100$ was added to the solution and shaking was continued for 48 h. 3) Cartilage tissue was rinsed thoroughly with Millipore water, and was digested with DNase and RNase overnight. 4) Tissue was further treated for $24 \mathrm{~h}$ in Tris- $\mathrm{HCl}$ buffer containing $10 \mathrm{~g} / \mathrm{L}$ Triton X-100. At last, the tissue was rinsed for $48 \mathrm{~h}$ with Millipore water, freeze dried, and sterilized with UV light. Tissue was stored at $-20^{\circ} \mathrm{C}$. Before use, the tissue was soaked in DMEM for $2 \mathrm{~h}$.

\section{ACMs were seeded with ADSCs}

The cultured ADSCs were digested and suspended and the cell density was adjusted to $2 \times 10^{7} / \mathrm{mL}$. About $0.2 \mathrm{~mL}$ cell suspension was added to the matrix surface, and incubated for $4 \mathrm{~h}$ in a $37^{\circ} \mathrm{C}$ incubator of $5 \% \mathrm{CO}_{2}$ and saturated humidity. Then, DMEM supplemented with $10 \%$ FBS was added, and incubation was continued. After 7 days, the culture medium was changed to chondrogenic differentiation medium containing $10 \mathrm{ng} / \mathrm{mL}$ TGF- $\beta 1$ (Amresoco, USA), $10 \mathrm{mg} / \mathrm{L}$ transferrin, $6.25 \mu \mathrm{g} / \mathrm{mL}$ insulin, $0.1 \mu \mathrm{M}$ dexamethasone, and $50 \mathrm{nM}$ vitamin C. The incubation was continued for 2 more weeks. 


\section{Construction of rabbit cartilage and grafting of the engineered cartilage tissue}

Twenty-four healthy adult New Zealand white rabbits was chosen, numbered, and randomly divided into 3 groups. Saturated sodium sulfate was used to remove the hair in the area $5 \mathrm{~cm}$ upper and lower of the articular region. The rabbits were anesthetized by the ear by iv injection of $3 \mathrm{mg} / \mathrm{kg}$ sodium isobarbital. Routine sterilization was performed, and a sterile cloth was padded. A 5-cm cut was made along the inner part of patellar ligament. When the joint chamber was approached, an aperture was drilled with 4-mm trephine at the femoral junction recess, and the drilling was stopped when the tissue seemed to bleed soon, without actual bleeding. For group A, the tissue-engineered cartilage was transplanted into the aperture. For group B, ACMs were transplanted. For group C, no treatment was administered at the defect area. The joint recess was rinsed with sterile saline, and each layer was carefully sewed. After operation, rabbits were raised freely in the cage, with im administration of penicillin after 1 week to prevent infection.

\section{Alcian blue staining}

The sample was fixed, decalcified, embedded in wax, and cut into slices along the sagittal plane perpendicular to the defect area. The sample was stained with Alcian blue for 5 min, and observed under the microscope.

\section{Immunohistochemical staining}

Type II collagen monoclonal antibody (Calbiochem, UK) was used for immunohistochemical staining. The primary antibody was the monoclonal mouse anti-rabbit type II collagen antibody, while the secondary antibody was the horseradish peroxidase goat anti-mouse polyclonal antibody. Diaminobenzidine was used for staining.

\section{Transmission electron microscopy (TEM) observation}

Samples were fixed, rinsed, dehydrated, soaked, wrapped, and cut into ultra-thin sections of $60-90 \mathrm{~nm}$. The sections were picked by 200 -mesh copper net, and stained with both lead citrate and uranyl acetate, and examined through TEM (Hitachi, Japan).

\section{RESULTS}

\section{Macroscopic evaluation}

Twelve weeks after surgery, experimental animals were sacrificed by aeroembolism. There was more complete filling at the defect area of group A. The repair tissue had the same color and property as normal articular cartilage. The repair tissue surface was smooth and there was a boundary ambiguous to that of the normal cartilage tissue. The binding was intense, not easy to separate by stripping (Figure 1A). For group B, there was no cartilage repair in the defect position. The original matrix condition was maintained. There was partial healing, but the surface was uneven, showed elevations and depressions, and the connecting boundary was 
clear (Figure 1B). For group C, there was no cartilage repair tissue. There was little healing at the bottom, but the repair tissue was little and could not function as filling (Figure 1C).

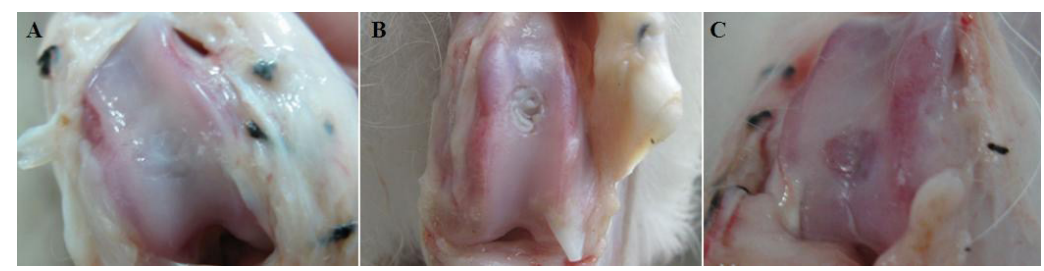

Figure 1. A. Defects, which were repaired by tissue-engineered cartilage, are smooth and there are no obvious boundaries between the defect and normal cartilage tissue in group A after 12 weeks. B. In group B, there is only original morphology of scaffold in the defects and the boundaries between the defect and normal cartilage tissue are obvious after 12 weeks. C. There is no repair in the defect in group C after 12 weeks.

\section{Histological evaluation}

For group A, most of the original repair tissue matrix was absorbed, the boundary between the repair tissue and normal cartilage was clear, and the cell distribution was not homogeneous. Alcian blue staining was positive and the cell distribution was not homogeneous (Figure 2A). Type II collagen immunochemical staining was positive (Figure 2B). For group $\mathrm{B}$, the original transplanted matrix was maintained in the repair tissue, but the connection to normal tissues was very loose. The sample could easily drop and break during slicing. The original graft tested positive for Alcian blue staining, and the boundary to the normal cartilage was clear. There was no cell structure in the matrix scaffold (Figure 2C). Type II collagen immunochemical staining was positive (Figure 2D). For group C, histological evaluation was not performed, because of lack of repair tissue or too little repair tissue.

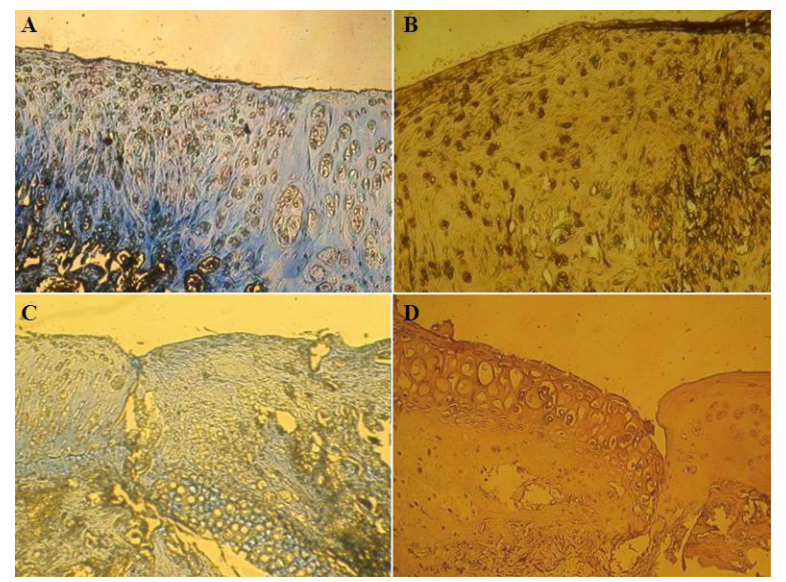

Figure 2. A. Group A, the boundary between repair tissue and normal cartilage is clear, and the cell distribution is not homogeneous; Alcian blue staining is positive (200X). B. Group A, type II collagen immunochemical staining is positive, the boundary between repair tissue and normal cartilage is clear, and the cell distribution is not homogeneous (200X). C. Group B, Alcian blue staining is positive; there is no cell structure in cartilage lacunae (200X). D. Group B, type II collagen immunochemical staining was positive, there was no cell structure in cartilage lacunae (200X). 


\section{TEM evaluation}

For group A, cell structures were observed in most recesses, and there was a large amount of homogenous cell matrix particles (Figure 3A). After scanning with the TEM, we observed morphological changes in cells on the cartilage matrix surface and the inner attaching part (Figure 3B). For group B, no chondrocytes were observed in the cartilage recesses (Figure 3C and D). For group C, TEM evaluation was not performed, because of lack of repair tissue or too little repair tissue.

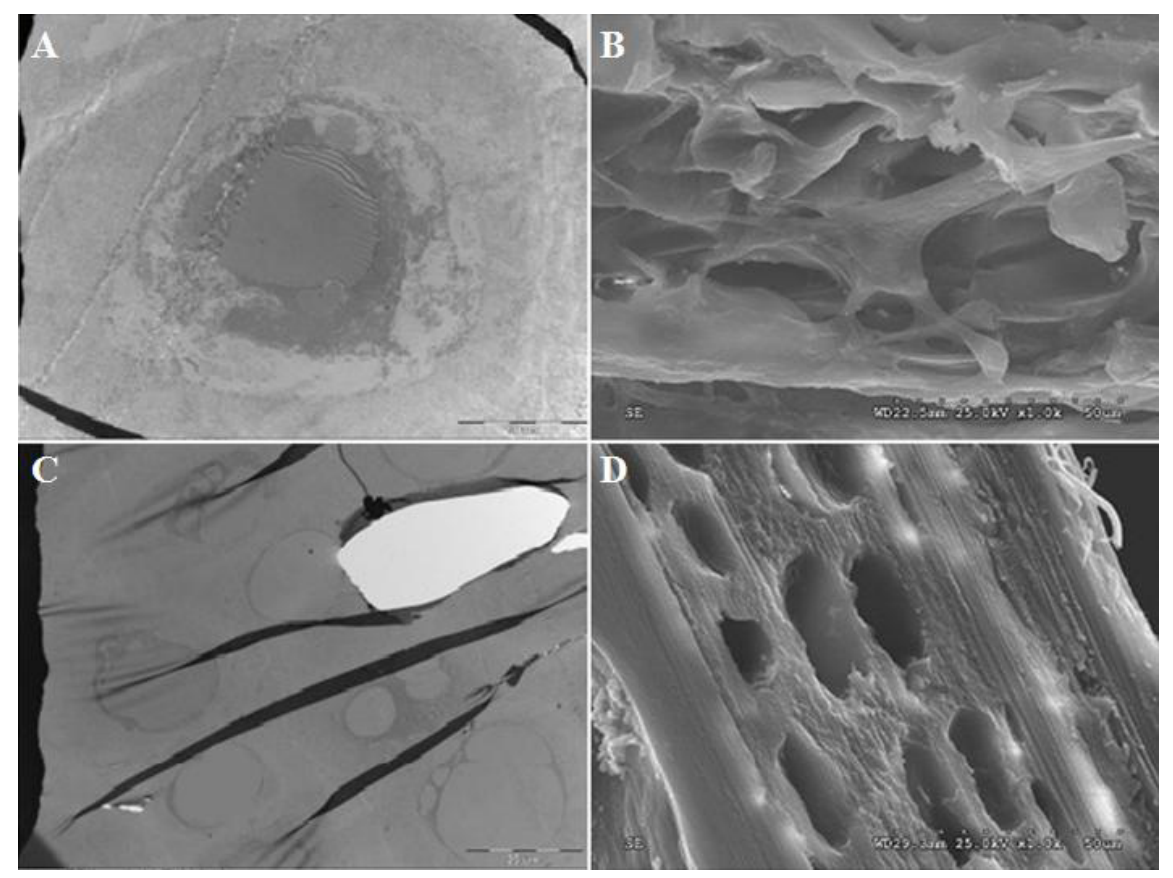

Figure 3. A. Group A, there is cell structure in most recesses, and a large amount of homogenous cell matrix particles $(5000 \mathrm{X})$. B. Group A, morphological changes of cells are observed on the cartilage matrix surface and inner attaching part (1000X). C. Group B, there are no chondrocytes in cartilage recesses (1800X). D. Group B, there are no chondrocytes on the cartilage matrix surface and inner attaching part (1800X).

\section{DISCUSSION}

Tissue engineering applies the rationale and technology of life sciences and engineering to generate various biological substitutes, which simulate the function and morphology of injured tissues or organs. In this study, ADSCs were seeded with ACMs and induced to differentiate into chondrocytes, in order to repair, improve, and regenerate injured or missing articular cartilage. Tissue-engineered cartilage generated by ADSCs was transplanted to the articular cartilage defect position. After 12 weeks, the defect was repaired. The repair tissue was rich in glucan and type II collagen, similar to normal articular cartilage. To some degree, the repair tissue repaired the joint cartilage defect, and recovered the joint function. 
ADSCs are adult stem cells from the middle germinal layer. They are easy to obtain, grow fast, and possess stable biological properties (Arrigoni et al., 2013; Laschke et al., 2013; Wu et al., 2013). Because they can definitely differentiate into chondrocytes (Kisiday et al., 2008), they are the "hot" cells of cartilage tissue engineering. Cartilage matrix is the filler of the spaces among chondrocytes, as well as the scaffold of the cartilage tissue. It is the factor maintaining the characteristics of biological mechanics at the joint cartilage. It has important functions in reducing joint friction, cushioning shaking, and transferring signals between cells (Rowland et al., 2013). In tissue engineering, cartilage matrix has an ideal 3-dimensional structure, physico-chemical properties, and good bio-compatibility. It is a reliable scaffold of ADSCs. In the process of inducing stem cells to differentiate into chondrocytes, there are 3 phases: single cell factor, cell factor combination, and sequential application of cell factors (Fromigue et al., 1998; Kim and Niyibizi, 2001; Shintani et al., 2013). The ideal induction strategy is to simulate continuous utilization of cell factor changes in the microenvironment during chondrocyte differentiation and development. However, this study is only at the beginning stage, and this technique is not mature yet. It is better to combine cell factors rather than using a single cell factor. In this study, TGF- $\beta 1$ and transferrin were used to induce the differentiation of ADSCs into chondrocytes and generate tissue-engineered cartilage. We tried to generate the ideal cartilage matrix by inducing ADSCs seeded with ACMs to differentiate into chondrocytes. It is hoped that this constructed cartilage can continuously secrete and degrade extracellular matrix spontaneously, and fuse with the normal cartilage to repair, improve, and regenerate injured or missing articular cartilage.

Nowadays, most scholars construct tissue-engineered cartilage by seeding differentiated stem cells on scaffolds. In the early stage of our experiments, we used this method, but we found that differentiated stem cells formed chondrocyte nodules, which were difficult to separate. Cell viability decreased after separation and soon the chondrocytes proliferated slower and even died, because of the inhibitory effect induced by the growing advantage of undifferentiated ADSCs. In addition, the dramatic extracellular environmental changes and complicated procedures increased the chance of contamination, and therefore, the result was not satisfactory. In this study, we seeded ADSCs on ACMs, and induced cells to differentiate into chondrocytes. With the help of growth factors and synergistic induction by type II collagen and GAG, ADSCs successfully differentiated into chondrocytes with high expression and secretion of type II collagen, which was the ideal result. However, the repair tissue cells had higher density than the normal cartilage cells, and the cell distribution was not homogenous, which needed further structure re-construction to obtain normal cartilage microstructure.

With respect to evaluation of our results, hematoxylin and eosin staining and immunohistochemistry showed that cells completely migrated to inner material, attached, proliferated, and differentiated into chondrocytes. After scanning the engineered cartilage tissue by TEM, we observed the expanding character of the cell in the material recesses and the matrix secretion conditions. The methods used showed and analyzed the experimental result more thoroughly and completely.

\section{ACKNOWLEDGMENTS}

Research supported by grants from the Guizhou Provincial Science and Technology Agency [\#NY (2006)3036 and \#J (2007)2227]. 


\section{REFERENCES}

Arrigoni E, De Girolamo L, Di Giancamillo A, Stanco D, et al. (2013). Adipose-derived stem cells and rabbit bone regeneration: histomorphometric, immunohistochemical and mechanical characterization. J. Orthop. Sci. 18: 331-339.

Badylak S and Obermiller J (2003). Extracellular matrix for myocardial repair. Heart Sury. Forum 6: 20-26.

Coburn JM, Bernstein N, Bhattacharya R, Aich U, et al. (2013). Differential response of chondrocytes and chondrogenicinduced mesenchymal stem cells to C1-OH tributanoylated N-acetylhexosamines. PLoS One 8: e58899.

Fromigue O, Marie PJ and Lomri A (1998). Bone morphogenetic protein-2 and transforming growth factor-beta2 interact to modulate human bone marrow stromal cell proliferation and differentiation. J. Cell Biochem. 68: 411-426.

Gimble J and Guilak F (2003). Adipose-derived adult stem cells: isolation, characterization, and differentiation potential. Cytotherapy 5: 362-369.

Grande DA, Breitbart AS, Mason J, Paulino C, et al. (1999). Cartilage tissue engineering: current limitations and solutions. Clin. Orthop. Relat. Res. (Suppl 367): S176-S185.

Karlsson C, Brantsing C, Svensson T, Brisby H, et al. (2007). Differentiation of human mesenchymal stem cells and articular chondrocytes: analysis of chondrogenic potential and expression pattern of differentiation-related transcription factors. J. Orthop. Res. 25: 152-163.

Kim MK and Niyibizi C (2001). Interaction of TGF-beta1 and rhBMP-2 on human bone marrow stromal cells cultured in collagen gel matrix. Yonsei Med. J. 42: 338-344.

Kisiday JD, Kopesky PW, Evans CH, Grodzinsky AJ, et al. (2008). Evaluation of adult equine bone marrow- and adiposederived progenitor cell chondrogenesis in hydrogel cultures. J. Orthop. Res. 26: 322-331.

Laschke MW, Schank TE, Scheuer C, Kleer S, et al. (2013). Three-dimensional spheroids of adipose-derived mesenchymal stem cells are potent initiators of blood vessel formation in porous polyurethane scaffolds. Acta Biomater. 9: 68766884.

Meretoja VV, Dahlin RL, Wright S, Kasper FK, et al. (2013). The effect of hypoxia on the chondrogenic differentiation of co-cultured articular chondrocytes and mesenchymal stem cells in scaffolds. Biomaterials 34: 4266-4273.

Mithoefer K, Williams RJ III, Warren RF, Potter HG, et al. (2005). The microfracture technique for the treatment of articular cartilage lesions in the knee. A prospective cohort study. J. Bone Joint Surg. Am. 87: 1911-1920.

Redman SN, Oldfield SF and Archer CW (2005). Current strategies for articular cartilage repair. Eur. Cell Mater. 9: 23-32.

Rowland CR, Lennon DP, Caplan AI and Guilak F (2013). The effects of crosslinking of scaffolds engineered from cartilage ECM on the chondrogenic differentiation of MSCs. Biomaterials 34: 5802-5812.

Shintani N, Siebenrock KA and Hunziker EB (2013). TGF-ss1 enhances the BMP-2-induced chondrogenesis of bovine synovial explants and arrests downstream differentiation at an early stage of hypertrophy. PLoS One 8: e53086.

Takao M, Uchio Y, Kakimaru H, Kumahashi N, et al. (2004). Arthroscopic drilling with debridement of remaining cartilage for osteochondral lesions of the talar dome in unstable ankles. Am. J. Sports Med. 32: 332-336.

van Lent PL and van den Berg WB (2013). Mesenchymal stem cell therapy in osteoarthritis: advanced tissue repair or intervention with smouldering synovial activation? Arthritis Res. Ther. 15: 112.

Vijayan S, Bartlett W, Bentley G, Carrington RW, et al. (2012). Autologous chondrocyte implantation for osteochondral lesions in the knee using a bilayer collagen membrane and bone graft: a two- to eight-year follow-up study. J. Bone Joint Surg. Br. 94: 488-492.

Wu L, Cai X, Zhang S, Karperien M, et al. (2013). Regeneration of articular cartilage by adipose tissue derived mesenchymal stem cells: perspectives from stem cell biology and molecular medicine. J. Cell Physiol. 228: 938-944.

Yoon IS, Chung CW, Sung JH, Cho HJ, et al. (2011). Proliferation and chondrogenic differentiation of human adiposederived mesenchymal stem cells in porous hyaluronic acid scaffold. J. Biosci. Bioeng. 112: 402-408.

Zuk PA, Zhu M, Ashjian P, De Ugarte DA, et al. (2002). Human adipose tissue is a source of multipotent stem cells. Mol. Biol. Cell 13: 4279-4295. 